\title{
Lesões de pele nos cuidados paliativos oncológicos: Estudo observacional
}

\author{
Skin lesions in oncology palliative care: Observational study \\ Lesiones cutáneas en cuidados paliativos oncológicos: Estudio observacional
}

Recebido: 22/04/2021 | Revisado: 29/04/2021 | Aceito: 06/05/2021 | Publicado: 21/05/2021

Maria Margarida Costa de Carvalho
ORCID: https://orcid.org/0000-0002-9102-1602
Hospital Ophir Loyola, Brasil
E-mail: dramargaridacarvalho@gmail.com
Winnie Taise Pena Macêdo
ORCID: https://orcid.org/0000-0002-2237-0788
Hospital Ophir Loyola, Brasil
E-mail: winnietaise@ gmail.com
Rayanne Bandeira Carneiro
ORCID: https://orcid.org/0000-0001-5761-9152
Hospital Ophir Loyola, Brasil
E-mail: rayannecarneiro7@ gmail.com
Érika de Cássia Lima Xavier
Hospital Ophir Loyola, Brasil
ORCID: https://orcid.org/0000-0003-0916-766X
E-mail: enferikaxavier@gmail.com
Ivonete Vieira Pereira Peixoto
ORCID: https://orcid.org/0000-0002-5463-9630
Universidade do Estado do Pará, Brasil
E-mail: ivonetep@ @otmail.com

\section{Resumo}

Objetivo: Descrever as características das lesões de pele do tipo lesão por pressão, ferida tumoral e úlcera terminal de Kennedy que ocorrem nos pacientes oncológicos em cuidados paliativos. Metodologia: Observacional do tipo transversal e analítico com abordagem quantitativa. Participaram 99 (100\%) pacientes, portadores de lesões de pele: $67(67,68 \%)$ com lesões tumorais, $28(28,28 \%)$ com lesões por pressão e $4(4,04 \%)$ com úlceras terminais de Kennedy. Foram incluídos os internados em quatro enfermarias e o ambulatório de feridas oncológicas do Hospital Ophir Loyola, no período de maio a novembro de 2019. Resultados: As lesões tumorais se apresentaram com feridas ulcerativas malignas $32(44,44 \%)$, exsudato $50(69,44 \%)$, sem odor $46(63,89 \%)$, não apresentaram necrose 42 $(58,33 \%)$, sem sangramento $40(55,56 \%)$, estadiamento $3(31,94 \%)$, localização na face $(25 \%)$, sem utilizar curativo $(33,33 \%)$ e frequência de curativo 1 vez ao dia 69 (95.83\%). Nas Lesões por pressão, as características foram exsudato $22(56,41 \%)$, sem odor $28(71,79 \%)$, necrose $27(69,23 \%)$, sangramento 32 (82,05\%), estadiamento II 17 $(43,59 \%)$, localização sacra $25(64,10 \%)$, utilizando curativo de hidrocolóide $15(38,46 \%)$ e frequência de curativo 1 vez ao dia $(64,10 \%)$ e as úlceras terminais de Kennedy, exsudato $4(66,67 \%)$, odor grau II 3 (50\%), necrose 4 $(66,67 \%)$, sangramento $4(66,67 \%)$, localização isquiática $3(50 \%)$, forma de pera $3(50 \%)$, utilizando curativo com clorexidina e metronidazol $3(50 \%)$. Conclusão: mostrou-se a importância da avaliação individual conforme as necessidades e as demandas de cada paciente para buscar conforto e qualidade de vida.

Palavras-chave: Enfermagem oncológica; Cuidados paliativos; Ferimentos e lesões; Cuidados paliativos na terminalidade da vida; Enfermagem de cuidados paliativos na terminalidade da vida.

\footnotetext{
Abstract

Objective: Describe the characteristics of skin lesions of the type pressure lesions, tumor wounds and Kennedy's terminal ulcers that occur in cancer patients in palliative care. Methodology: Observational, cross-sectional and analytical with a quantitative approach. 99 (100\%) patients with skin lesions participated: 67 (67.68\%) with tumor lesions, 28 (28.28\%) with pressure injuries and 4 (4.04\%) with Kennedy's terminal ulcers. Patients admitted to four wards and the oncological wounds outpatient clinic at Ophir Loyola Hospital, from May to November 2019, were included. Results: Tumor lesions presented with malignant ulcerative wounds 32 (44.44\%), exudate 50 (69.44\%), without odor $46(63.89 \%)$, did not present necrosis $42(58.33 \%)$, without bleeding 40 (55.56\%), staging $3(31.94 \%)$, location on the face (25\%), without using a dressing $(33.33 \%)$ and frequency of dressing once a day $69(95.83 \%)$. In pressure injuries, the characteristics were exudate $22(56.41 \%)$, no odor $28(71.79 \%)$, necrosis $27(69.23 \%)$, bleeding $32(82.05 \%)$, staging II $17(43,59 \%)$, sacred location $25(64.10 \%)$, using hydrocolloid dressing $15(38.46 \%)$ and frequency of dressing once a day $(64.10 \%)$ and Kennedy's terminal ulcers, exudate 4 ( $66.67 \%)$, grade II odor 3 $(50 \%)$, necrosis $4(66.67 \%)$, bleeding $4(66.67 \%)$, sciatic location $3(50 \%)$, pear shape $3(50 \%)$, using a dressing with
} 
chlorhexidine and metronidazole $3(50 \%)$. Conclusion: it was shown the importance of individual assessment according to the needs and demands of each patient to seek comfort and quality of life.

Keywords: Oncology nursing; Palliative care; Wounds and injuries; Hospice care; Hospice and palliative care nursing.

\section{Resumen}

Objetivo: Describir las características de las lesiones cutáneas del tipo lesiones por presión, heridas tumorales y úlceras terminales de Kennedy que se presentan en pacientes oncológicos en cuidados paliativos. Metodología: observacional, transversal y analítica con enfoque cuantitativo. Participaron 99 (100\%) pacientes con lesiones cutáneas: $67(67,68 \%)$ con lesiones tumorales, $28(28,28 \%)$ con lesiones por presión y $4(4,04 \%)$ con úlceras terminales de Kennedy. Se incluyeron los pacientes ingresados en cuatro salas y el ambulatorio de heridas oncológicas del Hospital Ophir Loyola, de mayo a noviembre de 2019. Resultados: Las lesiones tumorales se presentaron con heridas ulcerativas malignas $32(44,44 \%)$, exudado $50(69,44 \%)$, sin olor $46(63,89 \%)$, no presentaron necrosis 42 $(58,33 \%)$, sin sangrado $40(55,56 \%)$, estadificación $3(31,94 \%)$, localización en la cara $(25 \%)$, sin usar vendaje $(33,33 \%)$ y frecuencia de vendaje una vez al día $69(95,83 \%)$. En las lesiones por presión, las características fueron exudado $22(56,41 \%)$, ausencia de olor $28(71,79 \%)$, necrosis $27(69,23 \%)$, sangrado $32(82,05 \%)$, estadificación II $17(43,59 \%)$, lugar sagrado 25 ( 64,10\%), uso de apósito hidrocoloide $15(38,46 \%)$ y frecuencia de apósito una vez al día $(64,10 \%)$ y úlceras terminales de Kennedy, exudado $4(66,67 \%)$, olor grado II $3(50 \%)$, necrosis $4(66,67 \%)$, sangrado $4(66,67 \%)$, localización ciática $3(50 \%)$, forma de pera $3(50 \%)$, utilizando un apósito con clorhexidina y metronidazol $3(50 \%)$. Conclusión: se demostró la importancia de la valoración individual de acuerdo con las necesidades y demandas de cada paciente para buscar comodidad y calidad de vida.

Palabras clave: Enfermería oncológica; Cuidados paliativos; Heridas y traumatismos; cuidados paliativos al final de la vida; Enfermería de cuidados paliativos al final de la vida.
\end{abstract}

\title{
1. Introdução
}

Dentre as doenças inseridas nos cuidados paliativos, há o câncer, uma das principais causas de morbidade e mortalidade em todo o mundo. O número de novos casos deverá aumentar cerca de $70 \%$ nas próximas duas décadas. O câncer é a segunda principal causa de morte no mundo e é responsável por 9,6 milhões de mortes em 2018. A nível global, uma em cada seis mortes são relacionadas à doença. Aproximadamente $70 \%$ das mortes por câncer ocorrem em países de baixa e média renda (WHO, 2018).

No Brasil, a estimativa para cada ano do triênio 2020-2022 aponta que ocorrerão 625 mil casos novos de câncer (450 mil, excluindo os casos de câncer de pele não melanoma). Em Belém, foram estimados 2.680 novos no ano de 2020 , com o número de novos casos entre as mulheres, superior ao dos homens: 1.550 contra 1.130. O Inca mostra que 185,43 mulheres belenenses, em cada grupo de 100 mil, contrairão um tipo de câncer. Entre os homens, serão 150,65 a cada 100 mil. Os cânceres mais comuns na população feminina de Belém no ano de 2020, foram o de pele, com 330 registros; de mama, com 320 casos; de estômago, com 130; e o de colo do útero, com 110. Os homens registraram 250 casos de câncer de pele; 140 de próstata e outros 140 de estômago (INCA, 2019).

A falência tegumentar é comum em pacientes oncológicos, originando as feridas, as quais podem ser ocasionadas pela patologia em si ou como por processos de agressão a pele decorrente da fragilidade que as pessoas se encontram em função do estado neurológico levando-os a imobilidade no leito ou a perda de autonomia (Carvalho; Amaral, 2013).

A problemática relacionada ao manejo de alterações de pele em clientes com doença avançada e/ou com risco de morte iminente inclui: fiabilidade da pele ao redor da lesão, exsudação excessiva, infecção, necrose, odor, sangramento, dor, falta de higienização e doenças concomitantes. Os cuidados visam o controle da dor e do odor, controle de exsudato e redução de curativos (Firmino, 2011; Carvalho; Amaral, 2013).

As feridas mais encontradas, nesses processos são as úlceras por pressão, úlceras terminais de Kennedy, úlceras arteriais e venosas, feridas resultantes de traumas ou cirurgias, feridas em consequência do diabetes e feridas neoplásica (Carvalho; Amaral, 2013). Nesta fase final de vida, os pacientes com câncer têm sua fisiologia alterada, como resultado de vários fatores como, por exemplo: nutrição, modificações da pele, radioterapia e medicações, o que reflete na maior 
susceptibilidade na ocorrência dessas lesões, ratificando a condição de frágil do indivíduo (Ripley; Collier, 2017).

As lesões oncológicas são definas pela quebra da integridade, devido a infiltração de células malignas do tumor na estrutura da pele, resultado da proliferação celular desordenada e induzida pelo processo de oncogênese. As lesões tumorais, são estadiadas segundo a seguinte classificação (Haisfield-Wolfe; Baxendale-Cox, 1999):

Estádio 1: Assintomática, pele íntegra de coloração avermelhada e/ou violácea, se apresentaria com um nódulo visível e bem delimitado;

Estádio 1N: Podendo ter dor e prurido, sem odor. Pele íntegra ou com pequeno orifício superficial com drenagem de secreção límpida, amarelada ou de aspecto purulento. Tecido de cor também avermelhada ou violácea com lesão seca ou úmida. Não há formação de tuneis ou crateras;

Estádio 2: Ferida aberta com tecido inflamatório, podendo haver dor e dor, que envolve derme e epiderme, formação de ulcerações superficiais que podem ser friáveis, sensíveis ao manuseio, com pouco exsudato ou secas. Tecido de coloração avermelhadas e/ou violáceas. Sem formação de tuneis porque não ultrapassam o tecido subcutâneo;

Estádio 3: Há presença de dor, odor e exsudato fétido, tem aspecto vegetativo. Feridas que envolvem derme, epiderme e subcutâneo, de profundidade regular, porem com bordas salientes e irregulares, presença de feridas satélites em risco de rupturas. Tecido friável com o leito de coloração predominantemente amarelado;

Estádio 4: Presença de dor, odor e exsudato abundante, invade profundas estruturas anatômicas, não conseguindo visualizar seus limites. O leito de coloração amarelada com tecido ao redor violáceo.

A pressão é considera o principal fator causador das lesões por pressão, sendo o efeito patológico no tecido passível de atribuição à intensidade da pressão, à duração desta e a tolerância tecidual (Blanes; Ferreira, 2016). Estas se classificam da seguinte forma: Lesão por Pressão no Estágio 1: Se apresenta como um Eritema não branqueável. Quando ocorre Eritema que embranquece e alterações na sensação, temperatura ou endurecimento, estas podem preceder as alterações visuais das quais não incluem descoloração roxa ou marrom, pois estes podem indicar lesão tissular profunda;

Lesão por Pressão no Estágio 2: Ocorre perda parcial da espessura da pele, deixando a derme exposta. O leito da ferida é viável, rosa ou vermelho, úmido e pode também apresentar-se como uma bolha cheia de soro, intacta ou rompida. O tecido subcutâneo e os mais profundos não são visíveis. Este estágio não deve ser usado para descrever o dano cutâneo associado à umidade, incluindo dermatite associada à incontinência, dermatite intertriginosa, lesões cutâneas relacionadas a adesivos médicos ou feridas traumáticas (rasgos na pele, queimaduras, escoriações).

Lesão por pressão em estágio 3: Ocorre perda de espessura total da pele, na qual o tecido adiposo (gordura) é visível na ferida. Tecido de granulação e o epíbole (bordas enroladas) estão frequentemente presentes. A profundidade do dano tecidual varia por localização anatômica; áreas de adiposidade significativa podem desenvolver feridas profundas. Fáscia, músculo, tendão, ligamento, cartilagem e / ou osso não estão expostos.

Lesão por Pressão no Estágio 4: há perda total da pele e dos tecidos como fáscia, músculo, tendão, ligamento, cartilagem ou osso expostos ou diretamente palpáveis na úlcera. A profundidade varia por localização anatômica. Se a escara obscurece a extensão da perda de tecido esta é uma lesão por pressão não classificável.

Lesão por Pressão não Classificável: Perda de pele e tecido de espessura total na qual a extensão do dano tecidual dentro da úlcera não pode ser confirmada porque é obscurecida por esfacelo ou escara. Se o esfacelo ou escara forem removidos, uma lesão por pressão no Estágio 3 ou Estágio 4 será revelada. Escaras estáveis (ou seja, secas, aderentes, intactas, sem eritema ou flutuação) no calcanhar ou no membro isquêmico não devem ser amolecidas ou removidas.

Lesão por Pressão Tissular Profunda: Descoloração vermelho escura, marrom, ou púrpura, persistente e que não embranquece. Pele intacta ou não intacta com área localizada de coloração vermelha, marrom-avermelhada, persistente, não- 
branqueada, vermelho-escuro ou separação epidérmica, revelando leito de ferida escuro ou bolha cheia de sangue. Não se deve utilizar esta categoria de lesão para descrever condições vasculares, traumáticas, neuropáticas ou dermatológicas.

As pessoas que chegam ao fim da vida podem experimentar um fenômeno chamado úlcera terminal de Kennedy (UTK). Neste período, surgem úlceras por pressão que podem ser detectadas no fim do processo de morte; comumente ocorrem na região sacra, com aparência de pera, borboleta ou ferradura, com bordas irregulares. Elas aparecem de forma súbita e o tecido mostra deterioração progressiva e rápida (Carvalho; Amaral, 2013).

A perda da integridade da pele, ocorrida nas últimas horas que antecedem a morte, foi notificada a primeira vez por Karen Kennedy, em 1983, na área sacral, numa unidade de cuidados intermediários do Byron Health Center, Estados Unidos. A úlcera se desenvolveu apesar das medidas preventivas instituídas. Na UTK a deterioração da pele apresenta-se de progressão rápida, mesmo no decurso de um único dia. Segundo Kennedy, cuidadores e familiares são surpreendidos com o aparecimento súbito da úlcera e, a equipe profissional participante do seu estudo observou que esse tipo de lesão anuncia quando a morte está mais próxima de ocorrer (Carvalho; Amaral, 2013).

Destarte, os enfermeiros na condição de líderes da equipe de enfermagem, têm se responsabilizado por prever e prover recursos humanos, materiais e estruturais, fundamentando-se em evidências científicas, para implantar medidas preventivas das alterações de pele. Entretanto, quando o desenvolvimento é inevitável, torna-se necessária a adoção de ações terapêuticas adequadas a fim de minimizar as suas consequências e evitar a evolução da sua gravidade. E ainda, contribuir, efetivamente, com o gerenciamento dos custos associados (Lima et al., 2016). A relevância da presente pesquisa está relacionada à oportunidade de difundir, um olhar mais criterioso nas alterações de pele no fim da vida.

Admitiu-se, dessa forma, como questão de pesquisa: Qual a incidência e como evoluem as lesões de pele do tipo lesão por pressão, feridas tumorais e as úlceras terminais de kennedy que ocorrem nos pacientes oncológicos em cuidados paliativos? Diante disto, o objetivo da pesquisa é descrever as características das lesões de pele do tipo lesão por pressão, ferida tumoral e úlcera terminal de Kennedy que ocorrem nos pacientes oncológicos em cuidados paliativos.

\section{Metodologia}

Tratou-se de um estudo de cunho observacional do tipo transversal e analítico com abordagem quantitativa. Estudos observacionais descrevem a situação em um dado momento e por este motivo frequentemente são classificados de forma errônea como descritivos. Possibilitam o primeiro momento de análise de uma associação, identificando dentro de uma população os desfechos existentes, onde se podem elencar fatores que podem ou não estar associados a esses desfechos em diferentes graus de associação (Polit; Beck, 2019).

Ressalta-se que esta pesquisa foi um projeto Guarda-Chuva, o qual é definido como um projeto amplo com amostras/informações autorizadas para vários objetivos podendo contemplar vários autores/alunos. A resolução 466/2012 aborda que a pesquisa guarda-chuva e uma situação bastante comum entre as pesquisas em Informática na Educação, assim como em outras áreas remetendo ao "projeto guarda-chuva".

Reforça-se que desta pesquisa derivaram-se dois outros trabalhos de conclusão da residência multiprofissional em oncologia, os quais foram intitulados: "Fatores Preditivos Para Ocorrência de Lesão Por Pressão em Pacientes Oncológicos em Cuidados Paliativos em Belém, Amazônia brasileira" e "Feridas Tumorais em Pacientes sob Cuidados Paliativos".

A pesquisa ocorreu no Hospital Ophir Loyola (HOL), principal referência em tratamento oncológico da rede de saúde pública do Estado do Pará. O HOL possui vinte e sete (27) leitos destinados aos cuidados paliativos sendo dez (10) voltados aos pacientes recebendo Cuidados Paliativos exclusivos, dez (10) com doença oncológica avançada necessitando de terapia renal substutiva e sete (07) aos pacientes em cuidados paliativos que estão realizando concomitantemente terapia modificadora da doença. 
O HOL possui ainda o Ambulatório de Feridas, o qual funciona de segunda a sexta, com horário previamente marcado atendendo em média vinte (20) pacientes por dia com todos os tipos de curativos e lesões. Conta ainda com o Primeiro Departamento de Câncer ou Clínica de Cabeça e Pescoço, o qual possui vinte e um leitos (21), para atendimento de pacientes cirúrgicos e o segundo Departamento de Câncer que possui vinte e nove (29) leitos destinados a pacientes com câncer em tórax, urologia e mama.

Fizeram parte da população todos os pacientes que apresentaram LPP, Lesão Tumoral e UTK, chegando ao número de 99 pacientes. Como o estudo foi realizado em cinco locais diferentes, optou-se por dividir o período de coleta de forma que em maio e junho de 2019 foi realizado na CCPO1, julho e agosto na CCPO2, setembro no ambulatório de curativos, outubro e novembro nos departamentos de câncer 1 e 2. Dessa forma, foi possível chegar a amostra de 117 lesões de pele. Todos os internados nesse período, foram examinados no momento da visita de enfermagem para identificação de lesões e possíveis riscos para desenvolvimento delas.

As variáveis deste estudo foram categóricas nominais, onde foram definidas por categorias que não tinham ordenação dentre elas, ex: sexo, tipo de lesão, diagnóstico, exsudato, sangramento, necrose, odor e etc, assim como as variáveis categóricas ordinais, onde tinham uma ordenação dentre elas, por exemplo escolaridade, faixa etária, estadiamento, PPS e BRADEN (Lakatos; Marconi, 2017). Participaram todos os pacientes internados na Clínica de Cuidados Paliativos 1 (maio e junho de 2019), Cuidados Paliativos 2 (julho e agosto de 2019), Primeiro departamento de câncer (outubro de 2019), Segundo Departamento de Câncer (novembro de 2019) e que frequentaram o Ambulatório de Feridas do HOL em setembro de 2019, os quais eram portadores de câncer e no mínimo um dos três tipos das lesões estudadas e realizando ou não terapia modificadora da doença oncológica.

Foram excluídos do estudo os pacientes que apresentaram exclusivamente lesões de outras etiologias e/ou que internaram e evoluíram a óbito sem terem sido avaliados antes pela pesquisadora, os que estavam com dor, dispneia ou outro sofrimento descompensado, os que estavam sem acompanhantes no momento da coleta, além de pacientes que não tinham diagnóstico oncológico.

A coleta de dados ocorreu no período de maio a novembro de 2019. O estudo contou com a contribuição de duas residentes de enfermagem dos Cuidados Paliativos do projeto Guarda-chuva. Os dados foram coletados apenas após aprovação do projeto pelo Comitê de Ética em Pesquisa e após o aceite e posterior assinatura do Termo de Consentimento Livre e Esclarecido pelo paciente ou cuidador responsável, onde continha as informações da pesquisa e da garantia do anonimato de ambos.

Durante a visita de enfermagem, foi realizada uma abordagem com cada familiar e paciente na qual a pesquisadora se apresentou e explicou os objetivos da pesquisa, solicitando a participação deles na mesma. Em seguida deu-se início ao preenchimento da ficha de avaliação das lesões, preenchida todos os dias no momento da visita de enfermagem. Este procedimento foi realizado diariamente com novos pacientes.

Para melhor identificação e avaliação, as lesões foram fotografadas e as avaliações do PPS e da BRADEN foram realizadas em tempo real pela autora. Havendo a necessidade de outros dados a serem acrescentados, o prontuário do paciente foi usado para este fim, pois o uso dele foi autorizado por meio do Termo de Autorização de Acesso aos Prontuários.

Após a coleta de dados foi elaborado uma planilha eletrônica, para armazenamento dos dados, no software Microsoft Excel 2016, na qual cada linha correspondeu a um caso e cada coluna a uma variável.

Para representação descritiva dos dados foram elaboradas tabelas representando as frequências absolutas e relativas para as variáveis categóricas e as medidas de tendência central (média e mediana) e assim como as medidas de dispersão (desvio-padrão e intervalo interquartil) para as variáveis numéricas.

A análise dos dados foi processada utilizando-se o programa Epi Info 7.2 e o programa Biostat 5.0. Para a análise de 
associação (análise bivariada) entre as variáveis categóricas independente idade, tipo de lesão e óbito utilizou-se o teste G, para analise entre a variável sexo e óbito utilizou-se o teste Qui-quadrado corrigido de Yates. Para comparar a média de idade entre os casos com óbito e sem óbito utilizou-se o teste t-student. Em todos os testes considerou-se nível de significância de 5\% (pvalor $<0,05)$.

A pesquisa respeitou as normas e diretrizes envolvendo seres humanos, contidas na Resolução no 466, de 12 de dezembro de 2012, do Conselho Nacional de Saúde (CNS), sendo autorizada pelo Comitê de ética em Pesquisa do Hospital Ophir Loyola e da Universidade do Estado do Pará - Centro de Ciências Biológicas e da Saúde, por intermédio do parecer de número 3.300.981.

\section{Resultados}

Para cada tabela foi atribuída uma frequência absoluta (n) de acordo com a amostra apresentada em cada uma delas. Isto se deu pelo fato de que alguns pacientes apresentaram mais de um tipo de lesão estudada, além de mais de um caso do mesmo tipo. Então optou-se por caracterizar os pacientes $(n=99)$ e as lesões $(n=117)$ separadamente, sendo que dentre as lesões, 72 foram do tipo Tumoral, 39 LPP e 06 UTK.

A Tabela 1 mostra as características dos 99 pacientes portadores das lesões estudadas na pesquisa, onde a maioria era do sexo feminino $(52,53 \%)$, de faixa etária maior ou igual a 60 anos $(53,54 \%)$, de baixa escolaridade $(66,66 \%)$, portadores de câncer de pele não melanoma $(24,24 \%)$ e de mama $(13,13 \%)$. Quanto a localização das lesões a maioria apresentou lesões em região sacra $(26,26 \%)$, face $(18,18 \%)$, e mama $(10,10 \%)$, dos quais, 67 pacientes apresentaram lesão tumoral $(67,68 \%), 28$ lesão por pressão $(28,28 \%)$ e 4 úlcera terminal de kennedy $(4,04 \%)$. E quase a metade evoluiu a óbito após o término do período da coleta de dados $(44,44 \%)$.

Tabela 1 - Caracterização dos pacientes portadores das lesões estudadas na pesquisa.

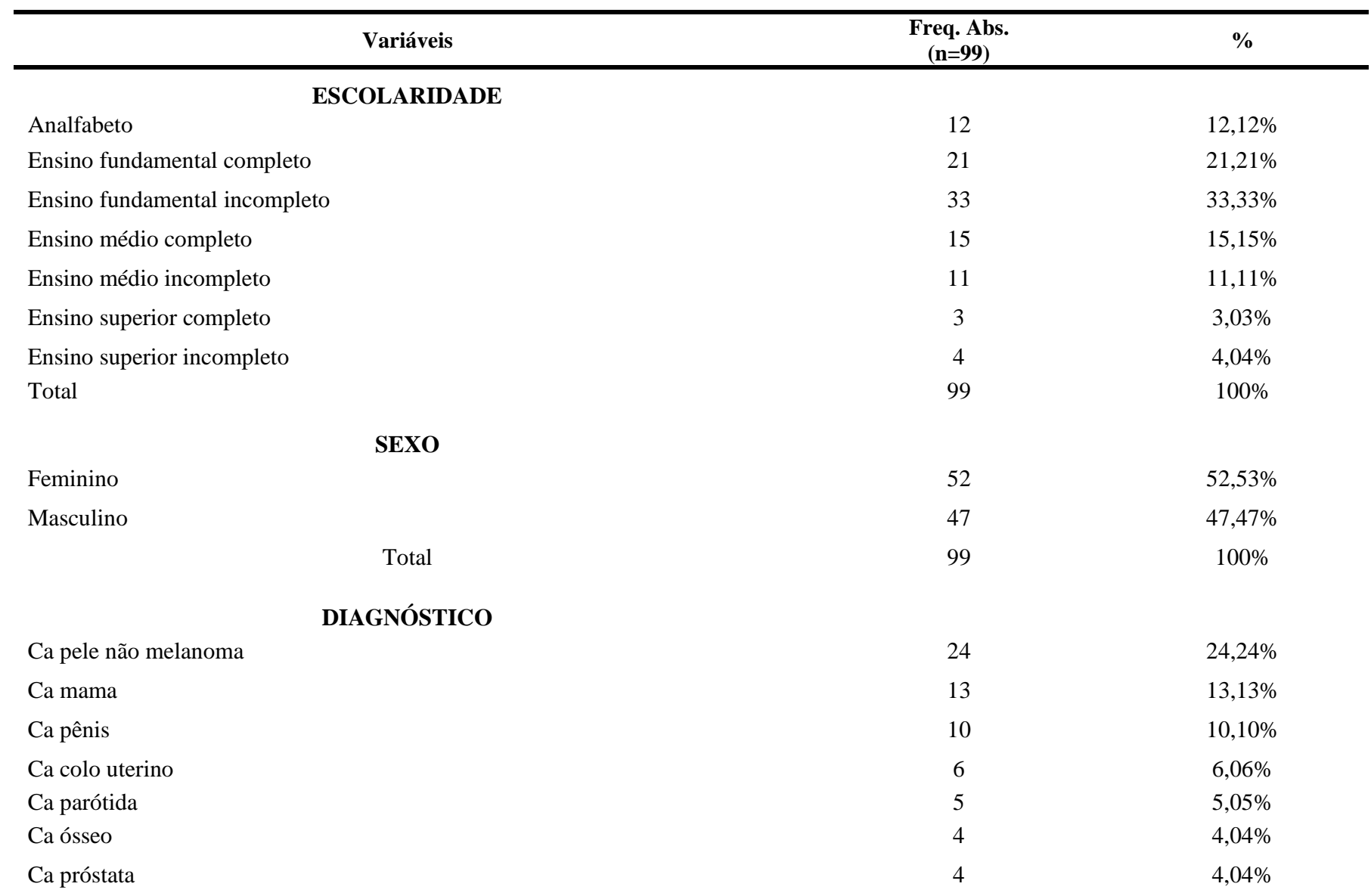


Ca laringe

Ca partes moles da cabeça

Ca boca

Ca canal anal

Ca encefálico

Ca língua

Ca reto

Ca rim

Ca tireóide

Ca cólon

Ca coração

Ca gástrico

Ca mediastino

Ca orofaringe

Ca ovário

Ca partes moles do tronco

Ca pulmão

Ca renal

Ca seios da face

Linfona não Hodgkin

Tu abdominal

Tu medular

Total

LOCAL

Sacra

Face

Mama

Cervical

Pênis

Inguinal

Pavilhão auricular

Clavicular

Ocular

Trocanter

Esternal

Axila

Boca

Calcanhar

Abdômen

Coluna dorsal

Isquiática

Maléolo

Membro inferior

Occipital

Pubiana

Total

\section{TIPO DE LESÃO}

LPP

Tumoral

UTK

Total

Não

Sim

Total

$20-29$

$30-39$

$40-49$

$50-59$

$\geq 60$

Total

ÓBITO

\section{IDADE}

$3,03 \%$

$3,03 \%$

$2,02 \%$

$2,02 \%$

$2,02 \%$

$2,02 \%$

$2,02 \%$

$2,02 \%$

$2,02 \%$

$1,01 \%$

$1,01 \%$

$1,01 \%$

$1,01 \%$

$1,01 \%$

$1,01 \%$

$1,01 \%$

$1,01 \%$

$1,01 \%$

$1,01 \%$

$1,01 \%$

$1,01 \%$

$1,01 \%$

$100 \%$

$26,26 \%$

$18,18 \%$

$10,10 \%$

$8,08 \%$

$6,06 \%$

$4,04 \%$

$4,04 \%$

$3,03 \%$

$3,03 \%$

$2,02 \%$

$2,02 \%$

$2,02 \%$

$2,02 \%$

$2,02 \%$

$1,01 \%$

$1,01 \%$

$1,01 \%$

$1,01 \%$

$1,01 \%$

$1,01 \%$

$1,01 \%$

$100,00 \%$

99

$28,28 \%$

$67,68 \%$

$4,04 \%$

$100 \%$ 
Fonte: Dados da Pesquisa.

Fazendo uma relação entre a idade dos 99 participantes da pesquisa e os 44 que evoluíram a óbito, foi observado que a mediana da idade e do tempo de vida dos participantes foi de 60 e 25 respectivamente (Tabela 2).

Tabela 2 - Relação da idade com o tempo de vida após o término da coleta de dados.

\begin{tabular}{|c|c|c|c|c|c|}
\hline Variável & $\mathbf{n}$ & Média $( \pm D P)$ & $\begin{array}{c}\text { Mediana } \\
(\mathrm{Q3}-\mathrm{Q1}) \\
\end{array}$ & $\begin{array}{c}\text { Mínim } \\
\text { o }\end{array}$ & Máximo \\
\hline Idade (anos) & $\begin{array}{l}9 \\
9\end{array}$ & $58,4(17,1)$ & $60(71-45)$ & 23 & 94 \\
\hline Tempo de vida após a coleta dos dados (em dias) & $\begin{array}{l}4 \\
4\end{array}$ & 62,2 & $25(62-8)$ & 1 & 445 \\
\hline
\end{tabular}

DP = Desvio-padrão. Fonte: Dados da Pesquisa.

A Tabela 3 trata da relação da variável/óbito com as variáveis idade, tipo de lesão e sexo, onde dos 99 pacientes do estudo, 44 evoluíram a óbito após a coleta de dados, dos quais 24 (46,2\%) eram do sexo feminino (de um total de 52 mulheres) e $23(43,4 \%)$ estavam na faixa etária dos maiores e iguais a 60 anos (de um total de 53 dos $\geq 60$ anos). De acordo com cada tipo de lesão, o óbito ocorreu em 82,1\% dos casos de LPP, 25,4\% das Feridas Tumorais, 100\% das Úlceras Terminais de Kennedy e além de apresentarem um tempo de vida após a coleta dos dados com mediana de 25 dias (Tabela 2).

Das variáveis mostradas na Tabela 3 a única que apresentou diferença estatisticamente significante foi variável tipo de lesão, onde alcançou um p-valor=0,0001.

Tabela 3 - Relação óbito com as variáveis idade, tipo de lesão e sexo.

\begin{tabular}{|c|c|c|}
\hline Variáveis & Óbito (\%) & p-valor \\
\hline \multicolumn{3}{|l|}{ IDADE } \\
\hline $20-29$ & $116,(7 \%)$ & \multirow{5}{*}{$0,41^{*}$} \\
\hline $30-39$ & $666,(7 \%)$ & \\
\hline $40-49$ & $7(41,2 \%)$ & \\
\hline $50-59$ & $7(50 \%)$ & \\
\hline$\geq 60$ & $23(43,4 \%)$ & \\
\hline \multicolumn{3}{|c|}{ TIPO DE LESÃO } \\
\hline LPP & $23(82,1 \%)$ & \multirow{3}{*}{$0,0001 *$} \\
\hline Tumoral & $17(25,4 \%)$ & \\
\hline UTK & $4(100 \%)$ & \\
\hline \multicolumn{3}{|l|}{ SEXO } \\
\hline Feminino & $24(46,2 \%)$ & \multirow[t]{2}{*}{$0,87 * *$} \\
\hline Masculino & $20(42,6 \%)$ & \\
\hline
\end{tabular}

*Teste G, **Qui-quadrado (Yates). Fonte: Dados da Pesquisa.

A Tabela 4 elucida que não houve interferência da idade na ocorrência dos óbitos, pois dos 99 pacientes, portadores das três lesões estudadas, morreram 44 que apresentaram uma mediana de idade de 60,5. E a mediana da idade dos 55 que não morreram foi de 60 ou seja, bem próxima dos que evoluíram a óbito. Nesta tabela se observa que a variável idade não apresentou diferença estatisticamente significante pois o p-valor foi de 0,56 . 
Tabela 4 - Interferência da variável idade na ocorrência dos óbitos.

\begin{tabular}{|c|c|c|c|c|c|c|c|}
\hline \multirow[b]{2}{*}{ Variável } & \multirow[b]{2}{*}{$\mathbf{n}$} & \multicolumn{2}{|c|}{ Não óbito } & \multirow[b]{2}{*}{$\mathbf{n}$} & \multicolumn{2}{|c|}{ Óbito } & \multirow[b]{2}{*}{ p-valor } \\
\hline & & Média ( $\pm D P)$ & $\begin{array}{c}\text { Mediana } \\
(\text { Q3 - Q1) } \\
\end{array}$ & & Média $( \pm D P)$ & $\begin{array}{c}\text { Mediana } \\
(\mathbf{Q 3}-\mathbf{Q 1}) \\
\end{array}$ & \\
\hline $\begin{array}{l}\text { Idade } \\
\text { (anos) }\end{array}$ & 55 & $57,6(17,7)$ & $60(69-44)$ & 44 & $59,5(16,5)$ & $60,5(72-46)$ & $0,56^{*}$ \\
\hline
\end{tabular}

$\mathrm{DP}=$ Desvio-padrão, Q1= primeiro quartil, Q3= terceiro quartil,*Teste t-student. Fonte: Dados da Pesquisa.

A Tabela 5 mostra as características das Feridas Tumorais e o manejo realizado com elas, onde das 72 Feridas Tumorais do estudo, 69,44\% delas eram exsudativas, 36,12\% apresentaram algum grau de odor, 58,33\% não tinham necrose e $55,56 \%$ não apresentaram sangramentos, o que pode estar relacionado ao estadiamento dessas lesões, onde o maior percentual foi de feridas tumorais de estadiamentos iniciais como $1,1 \mathrm{~N}$ e 2 , localizadas a maioria na região da face $(25,00 \%)$, mama $(13,89 \%)$ e cervical $(11,11 \%)$.

Esta Tabela além das características, aborda as condutas realizadas pela equipe de enfermagem para este tipo de lesão, onde observou-se uma repetição do uso de clorexidina degermante, metronidazol e vaselina, porem com uma vasta heterogenicidade nas associações destes materiais. Por fim, para a frequência de troca dos curativos o que se observou foi a predominância da realização de pelo menos uma vez ao dia $(95,83 \%)$.

Tabela 5 - Características das Feridas Tumorais e Manejo.

\begin{tabular}{|c|c|c|}
\hline Variáveis & $\begin{array}{c}\text { Freq. Abs. } \\
(\mathrm{n}=72)\end{array}$ & $\%$ \\
\hline \multicolumn{3}{|l|}{ FORMA } \\
\hline FERIDA FUNGOSA MALIGNA & 28 & $38,89 \%$ \\
\hline FERIDA FUNGOSA MALIGNA ULCERADA & 12 & $16,67 \%$ \\
\hline FERIDA ULCERATIVA MALIGNA & 32 & $44,44 \%$ \\
\hline Total & 72 & $100 \%$ \\
\hline \multicolumn{3}{|l|}{ EXSUDATO } \\
\hline NÃO & 22 & $30,56 \%$ \\
\hline SIM & 50 & $69,44 \%$ \\
\hline Total & 72 & $100 \%$ \\
\hline \multicolumn{3}{|c|}{ GRAU ODOR } \\
\hline GRAU I & 12 & $16,67 \%$ \\
\hline GRAU II & 13 & $18,06 \%$ \\
\hline GRAU III & 1 & $1,39 \%$ \\
\hline NÃO & 46 & $63,89 \%$ \\
\hline Total & 72 & $100 \%$ \\
\hline \multicolumn{3}{|l|}{ NECROSE } \\
\hline NÃO & 42 & $58,33 \%$ \\
\hline SIM & 30 & $41,67 \%$ \\
\hline Total & 72 & $100 \%$ \\
\hline \multicolumn{3}{|c|}{ SANGRAMENTO } \\
\hline NÃO & 40 & $55,56 \%$ \\
\hline SIM & 32 & $44,44 \%$ \\
\hline Total & 72 & $100 \%$ \\
\hline
\end{tabular}




\section{ESTADIAMENTO}

1

$1 \mathrm{~N}$

2

3

4

Total

\section{LOCAL}

$\begin{array}{lrr}\text { Abdomen } & 1 & 1,39 \% \\ \text { Anal } & 2 & 2,78 \% \\ \text { Axilar } & 2 & 2,78 \% \\ \text { Boca } & 2 & 2,78 \% \\ \text { Cervical } & 8 & 11,11 \% \\ \text { Clavicular } & 3 & 4,17 \% \\ \text { Esternal } & 2 & 2,78 \% \\ \text { Face } & 18 & 25,00 \% \\ \text { Iguinal } & 5 & 6,94 \% \\ \text { Mama } & 10 & 13,89 \% \\ \text { Membro inferior } & 1 & 1,39 \% \\ \text { Occipital } & 1 & 1,39 \% \\ \text { Ocular } & 3 & 4,17 \% \\ \text { Pavilhão auricular } & 3,56 \% \\ \text { Pênis } & 4 & 8,33 \% \\ \text { Pubiana } & 4,17 \% \\ \text { Trocanter } & 6 & 1,39 \% \\ \text { Total } & 3 & 100,00 \%\end{array}$

\section{PRODUTOS UTILIZADOS}

Adrenalina + vaselina

Clorexidina degermante

$5,56 \%$

Clorexidina degermante + gazes acolchoadas

$1,39 \%$

Clorexidina degermante + hidrogel

Clorexidina degermante + metronidazol

$6,94 \%$

Clorexidina degermante + metronidazol + vaselina

$2,78 \%$

Clorexidina degermante + polihexanida + hidrogel

Clorexidina degermante + pomada ácido fusidico

Clorexidina degermante + vaselina

$1,39 \%$

Clorexidina degermante + vaselina + adrenalina

$1,39 \%$

$6,94 \%$

Clorexidina degermante + metronidazol + hidrogel

$1,39 \%$

Metronidazol + cmc com ag

$1,39 \%$

Metronidazol + colagenase

$2,78 \%$

Metronidazol + vaselina

$1,39 \%$

Metronidazol + vaselina + cmc com ag

Nada

Polihexanida sol + gazes simples

Polihexanida sol + metronidazol + age + hidrogel 
Sol fis $0,9 \%+$ gazes simples

Sol fis $0,9 \%$ gelado + vaselina

Vaselina

Total

1XDIA

2XDIA

3XDIA

Total

\section{FREQUÊNCIA DA TROCA DO CURATIVO}

7

1

5

72

$9,72 \%$

$1,39 \%$

$6,94 \%$

$100,00 \%$

Fonte: Dados da Pesquisa.

A Tabela 6 se refere as características das Lesões por Pressão e o manejo empregado a elas. De um total de 39 Lesões por Pressão, a maioria apresentou exsudato $(56,41 \%)$, porém sem odor $(71,79 \%)$, sem necrose $(69,23 \%)$ e sem sangramento $(82,05 \%)$, o que também pode estar relacionado diretamente ao estadiamento delas, no qual a maioria encontrava-se em estágio 1 e $2(28,21 \%$ e 43,59\%). A região sacra também foi a de maior ocorrência (64,10\%), seguida pela região do calcanhar $(17,95 \%)$, e o produto mais utilizado foi o Hidrocolóide $(38,46 \%)$. As trocas dos curativos foram realizadas em maior frequência, uma vez ao dia $(64,10 \%)$ e a cada 7 dias $(23,08 \%)$.

Tabela 6 - Características das Lesões por Pressão e Manejo.

\begin{tabular}{|c|c|c|c|}
\hline & Variáveis & $\begin{array}{c}\text { Freq. Abs. } \\
(\mathbf{n}=39)\end{array}$ & $\%$ \\
\hline & EXSUDATO & & \\
\hline NÃO & & 17 & $43,59 \%$ \\
\hline SIM & & 22 & $56,41 \%$ \\
\hline \multirow[t]{2}{*}{ Total } & & 39 & $100 \%$ \\
\hline & GRAU ODOR & & \\
\hline GRAU I & & 8 & $20,51 \%$ \\
\hline GRAU II & & 3 & $7,69 \%$ \\
\hline GRAU III & & 0 & $0 \%$ \\
\hline NÃO & & 28 & $71,79 \%$ \\
\hline \multirow[t]{2}{*}{ Total } & & 39 & $100 \%$ \\
\hline & NECROSE & & \\
\hline NÃO & & 27 & $69,23 \%$ \\
\hline SIM & & 12 & $30,77 \%$ \\
\hline \multirow[t]{2}{*}{ Total } & & 39 & $100 \%$ \\
\hline & SANGRAMENTO & & \\
\hline NÃO & & 32 & $82,05 \%$ \\
\hline SIM & & 7 & $17,95 \%$ \\
\hline Total & & 39 & $100 \%$ \\
\hline
\end{tabular}




\section{ESTADIAMENTO}

EST I

$11 \quad 28,21 \%$

EST II

$17 \quad 43,59 \%$

EST III

$3 \quad 7,69 \%$

EST IV

LP TISSULAR PROFUNDA

$1 \quad 2,56 \%$

NÃO CLASSIFICAVEL

$10,26 \%$

Total

$7,69 \%$

$39 \quad 100 \%$

\section{LOCAL}

Calcanhar

Coluna dorsal

Escapular

Isquiatica

Maléolo

Occipital

Sacra

Trocanter

Total

$\begin{array}{cr}7 & 17,95 \% \\ 1 & 2,56 \% \\ 1 & 2,56 \% \\ 1 & 2,56 \% \\ 1 & 2,56 \% \\ 2 & 5,13 \% \\ 25 & 64,10 \% \\ 1 & 2,56 \% \\ 39 & 100,00 \%\end{array}$

\section{PRODUTOS UTILIZADOS}

$\begin{array}{lcc}\text { AGE } & 4 & 10,26 \% \\ \text { CLOREXIDINA DEGERMANTE + METRONIDAZOL + VASELINA } & 2 & 5,13 \% \\ \text { CMC COM AG + ESPUMA DE POLIURETANO COM AG + FILME TRANSPARENTE } & 1 & 2,56 \% \\ \text { ESPUMA DE POLIURETANO COM AG + FILME TRANSPARENTE } & 1 & 2,56 \% \\ \text { GAZES ACOLCHOADAS + ATADURAS } & 2 & 5,13 \% \\ \text { HIDROCOLOIDE } & 15 & 38,46 \% \\ \text { HIDROGEL } & 13 & 33,33 \% \\ \text { NADA } & 1 & 2,56 \% \\ \text { Total } & 39 & 100,00 \%\end{array}$

\section{FREQUÊNCIA DA TROCA DE CURATIVOS}

\begin{tabular}{lcc} 
1XDIA & 25 & $64,10 \%$ \\
3DIAS & 3 & $7,69 \%$ \\
5DIAS & 1 & $2,56 \%$ \\
7DIAS & 9 & $23,08 \%$ \\
NÃO INFORMADO & 1 & $2,56 \%$ \\
Total & 39 & $100,00 \%$ \\
\hline
\end{tabular}

Fonte: Dados da Pesquisa.

A Tabela 7 mostra as características da Úlceras Terminais de Kennedy e seu manejo, onde das 6 lesões estudadas, a maioria apresentava exsudato $(66,67 \%)$, odor grau II (50\%), necrose $(66,67 \%)$, tinham forma de Pera (50\%), ocorreu na região sacra (50\%). Para o manejo, a equipe de enfermagem usou em sua maioria, a associação dos produtos clorexidina e metronidazol e vaselina (50\%), e o hidrogel em somente um dos casos (16,67\%). As trocas de curativos ocorreram uma vez ao dia em 5 casos $(83,33 \%)$. 
Tabela 7 - Características das Úlceras Terminais de Kennedy e Manejo.

\begin{tabular}{|c|c|c|}
\hline Variáveis & $\begin{array}{c}\text { Freq. Abs. } \\
(n=6)\end{array}$ & $\%$ \\
\hline EXSUDATO & & \\
\hline NÃO & 2 & $33,33 \%$ \\
\hline SIM & 4 & $66,67 \%$ \\
\hline Total & 6 & $100 \%$ \\
\hline GRAU ODOR & & \\
\hline GRAU I & 1 & $16,67 \%$ \\
\hline GRAU II & 3 & $50,0 \%$ \\
\hline GRAU III & 0 & $0 \%$ \\
\hline NÃO & 2 & $33,33 \%$ \\
\hline Total & 6 & $100 \%$ \\
\hline NECROSE & & \\
\hline NÃO & 2 & $33,33 \%$ \\
\hline SIM & 4 & $66,67 \%$ \\
\hline Total & 6 & $100 \%$ \\
\hline SANGRAMENTO & & \\
\hline NÃO & 4 & $66,67 \%$ \\
\hline SIM & 2 & $33,33 \%$ \\
\hline Total & 6 & $100 \%$ \\
\hline FORMA & & \\
\hline Borboleta & 1 & $16,66 \%$ \\
\hline Ferradura & 2 & $33,33 \%$ \\
\hline Pera & 3 & $50 \%$ \\
\hline Total & 6 & $100 \%$ \\
\hline LOCAL & & \\
\hline Coluna dorsal & 2 & $33,33 \%$ \\
\hline Isquiatica & 1 & $16,67 \%$ \\
\hline Sacra & 3 & $50,00 \%$ \\
\hline Total & 6 & $100,00 \%$ \\
\hline \multicolumn{3}{|l|}{ PRODUTOS UTILIZADOS } \\
\hline CLOREXIDINA DEGERMANTE + METRONIDAZOL + VASELINA & 3 & $50,00 \%$ \\
\hline HIDROCOLOIDE & 2 & $33,33 \%$ \\
\hline SOL FIS 0,9\% + HIDROGEL & 1 & $16,67 \%$ \\
\hline Total & 6 & $100,00 \%$ \\
\hline \multicolumn{3}{|l|}{ FREQUÊNCIA DA TROCA DE CURATIVO } \\
\hline 1XDIA & 5 & $83,33 \%$ \\
\hline 7DIAS & 1 & $16,67 \%$ \\
\hline Total & 6 & $100,00 \%$ \\
\hline
\end{tabular}


Os pacientes que apresentaram Lesão tumoral tiveram um tempo de vida com mediana de 61 dias, assim como se observa na Tabela 8 .

Tabela 8 - Avaliação do tempo de vida dos pacientes com lesão Tumoral.

\begin{tabular}{cccccc}
\hline Variável & N & Média ( $\pm \mathbf{D P})$ & $\begin{array}{c}\text { Mediana } \\
(\mathbf{Q 3}-\mathbf{Q 1})\end{array}$ & Mínimo & Máximo \\
\hline Tempo de vida após a coleta de dados (em dias) & 1 & $119( \pm 138,8)$ & $61(149-24)$ & 3 & 445 \\
\hline
\end{tabular}

DP = Desvio-padrão. Fonte: Dados da Pesquisa.

Os 17 pacientes que evoluíram a óbito portadores de lesão tumoral, apresentaram em sua maioria PPS entre 30\%, 20\% e $10 \%$ (7, 5 e 4 pacientes, respectivamente). Os estadiamento que mais ocorreram foram 3 e 4 ( 8 e 5 pacientes). Por fim, no que se refere ao tipo de câncer, os de maior número, onde somados deram 58,83\% dos casos foi em primeiro lugar, o câncer de mama, seguido do câncer de pênis e do câncer de pele não melanoma.

Tabela 9 - Relação dos 17 pacientes portadores de Lesão Tumoral que evoluíram a óbito com as variáveis PPS, Estadiamento e diagnóstico.

\begin{tabular}{|c|c|c|}
\hline Variáveis & $\begin{array}{c}\text { Freq. Abs. } \\
(\mathbf{n}=17)\end{array}$ & $\%$ \\
\hline \multicolumn{3}{|l|}{ PPS } \\
\hline $10 \%$ & 4 & $23,53 \%$ \\
\hline $20 \%$ & 5 & $29,41 \%$ \\
\hline $30 \%$ & 7 & $41,18 \%$ \\
\hline $60 \%$ & 1 & $5,88 \%$ \\
\hline Total & 17 & $100 \%$ \\
\hline \multicolumn{3}{|l|}{ ESTADIAMENTO } \\
\hline 1 & 1 & $5,88 \%$ \\
\hline $1 \mathrm{~N}$ & 0 & $0 \%$ \\
\hline 2 & 3 & $17,65 \%$ \\
\hline 3 & 8 & $47,06 \%$ \\
\hline 4 & 5 & $29,41 \%$ \\
\hline Total & 17 & $100 \%$ \\
\hline \multicolumn{3}{|l|}{ DIAGNÓSTICO } \\
\hline CA MAMA & 4 & $23,53 \%$ \\
\hline CA PÊNIS & 3 & $17,65 \%$ \\
\hline CA PELE NÃO MELANOMA & 3 & $17,65 \%$ \\
\hline CA BOCA & 1 & $5,88 \%$ \\
\hline CA LARINGE & 1 & $5,88 \%$ \\
\hline CA LÍNGUA & 1 & $5,88 \%$ \\
\hline CA OROFARINGE & 1 & $5,88 \%$ \\
\hline CA ÓSSEO & 1 & $5,88 \%$ \\
\hline CA SEIOS DA FACE & 1 & $5,88 \%$ \\
\hline LINFONA NÃO HODGKIN & 1 & $5,88 \%$ \\
\hline Total & 17 & $100 \%$ \\
\hline
\end{tabular}


Fonte: Dados da Pesquisa.

Os pacientes que apresentaram as Úlceras Terminais de Kennedy evoluíram a óbito em média com 12,5 dias, e o que mais tempo viveu chegou a 29 dias. Este grupo alcançou uma mediana de tempo de vida de 9 dias após a coleta de dados, assim como está descrito na Tabela 10.

Tabela 10 - Avaliação do tempo de vida dos pacientes com Úlcera Terminal de Kennedy.

\begin{tabular}{cccccc}
\hline Variável & N & Média $( \pm D P)$ & $\begin{array}{c}\text { Mediana } \\
(\mathbf{Q}-\mathbf{Q 1})\end{array}$ & Mínimo & Máximo \\
\hline Tempo de vida após a coleta dos dados (em dias) & 4 & $12,5( \pm 11,8)$ & $9(17-5)$ & 3 & 29 \\
\hline
\end{tabular}

DP = Desvio-padrão. Fonte: Dados da Pesquisa.

A Tabela 11 mostra a relação entre as variáveis óbito, PPS e Diagnóstico, dentre os 4 pacientes portadores das Úlceras Terminais de kennedy encontradas no estudo. Nela observa-se que o óbito ocorreu em 100\% dos casos, e que o PPS permaneceu em torno de $20 \%$ e $10 \%$, ocorridos em 2 pacientes cada, e o diagnóstico se mostrou bem heterogêneo, sendo um caso de câncer de colo uterino, um de câncer de canal anal, um de câncer renal e por fim, um de câncer de reto.

Tabela 11 - Relação dos 4 pacientes portadores de Úlceras Terminais de Kennedy que evoluíram a óbito com as variáveis PPS, estadiamento e diagnóstico.

\begin{tabular}{lccc}
\hline & Variáveis & $\begin{array}{c}\text { Freq. Abs. } \\
(\mathbf{n = 4})\end{array}$ & $\%$ \\
\hline & PPS & & \% \\
$10 \%$ & & 2 & $29,53 \%$ \\
$20 \%$ & & 2 & $100 \%$ \\
Total & DIAGNÓSTICO & 4 & \\
& & & $25 \%$ \\
CA COLO UTERINO & & 1 & $25 \%$ \\
CA CANAL ANAL & & 1 & $25 \%$ \\
CA RENAL & & 1 & $25 \%$ \\
CA RETO & & 1 & $100 \%$ \\
Total & & 4 & 2 \\
\hline
\end{tabular}

Fonte: Dados da Pesquisa.

A tabela 12 mostra que os 39 pacientes com LPP apresentaram valores da escala de Braden com mediana de 11 e que, destes morreram 23, dos quais alcançaram mediana de tempo de vida em torno de 12 dias após a coleta de dados. 
Tabela 12 - Média, desvio-padrão, mediana, $3^{\circ}$ quartil, $1^{\circ}$ quartil, mínimo e máximo das variáveis Braden e tempo de vida após a coleta de dados dos pacientes portadores de LPP.

\begin{tabular}{lccccc}
\hline \multicolumn{1}{c}{ Variável } & N & Média $( \pm \mathbf{D P})$ & $\begin{array}{c}\text { Mediana } \\
(\mathbf{Q 3}-\mathbf{Q 1})\end{array}$ & $\begin{array}{c}\text { Mínim } \\
\mathbf{0}\end{array}$ & $\begin{array}{c}\text { Máxim } \\
\mathbf{0}\end{array}$ \\
\hline & & & & & \\
BRADEN & 3 & $11,4( \pm 2,7)$ & $11(13-10)$ & 7 & 19 \\
& 9 & & & & \\
Tempo de vida após a coleta de dados (em dias) & 2 & $28,8( \pm 41,3)$ & $12(42-6)$ & 1 & 195 \\
\hline
\end{tabular}

DP = Desvio-padrão. Fonte: Dados da Pesquisa.

A Tabela 13 mostra a relação das variáveis PPS, BRADEN e Diagnóstico com os 23 casos de óbitos dos portadores de LPP, onde dentre os óbitos ocorridos, a maioria apresentou PPS de 30\%, 20\% e 10\%. No que se refere ao estadiamento, para os casos de óbitos o mesmo não apresentou relação com os estadiamentos mais avançados, pois os que mais ocorreram foi o estágio 1 e 2 com 9 e 10 casos respectivamente. Em relação ao diagnostico, o câncer de colo uterino ocorreu em 4 casos.

Tabela 13 - Interferência das variáveis PPS, Estadiamento e Diagnóstico para os óbitos dos pacientes portadores de LPP.

\begin{tabular}{|c|c|c|}
\hline Variáveis & $\begin{array}{c}\text { Freq. Abs. } \\
(n=23)\end{array}$ & $\%$ \\
\hline \multicolumn{3}{|l|}{ PPS } \\
\hline $10 \%$ & 6 & $26,09 \%$ \\
\hline $20 \%$ & 3 & $13,04 \%$ \\
\hline $30 \%$ & 10 & $43,48 \%$ \\
\hline $40 \%$ & 3 & $13,04 \%$ \\
\hline $50 \%$ & 1 & $4,35 \%$ \\
\hline Total & 23 & $100 \%$ \\
\hline \multicolumn{3}{|l|}{ ESTADIAMENTO } \\
\hline EST 1 & 9 & $39,13 \%$ \\
\hline EST 2 & 10 & $43,48 \%$ \\
\hline EST 3 & 1 & $4,35 \%$ \\
\hline EST 4 & 0 & $0 \%$ \\
\hline LP TISSULAR PROFUNDA & 1 & $4,35 \%$ \\
\hline LP TISSULAR PROFUNDA & 1 & $4,35 \%$ \\
\hline NÃO CLASSIFICAVEL & 1 & $4,35 \%$ \\
\hline Total & 23 & $100 \%$ \\
\hline \multicolumn{3}{|l|}{ DIAGNÓSTICO } \\
\hline CA COLO UTERINO & 4 & $17,39 \%$ \\
\hline CA PRÓSTATA & 3 & $13,04 \%$ \\
\hline CA RIM & 2 & $8,70 \%$ \\
\hline CA ENCEFÁLICO & 2 & $8,70 \%$ \\
\hline CA BOCA & 1 & $4,35 \%$ \\
\hline CA CANAL ANAL & 1 & $4,35 \%$ \\
\hline CA CÓLON & 1 & $4,35 \%$ \\
\hline
\end{tabular}




\begin{tabular}{ccc} 
CA GÁSTRICO & 1 & $4,35 \%$ \\
CA MAMA & 1 & $4,35 \%$ \\
CA ÓSSEO & 1 & $4,35 \%$ \\
CA OVÁRIO & 1 & $4,35 \%$ \\
CA PARÓTIDA & 1 & $4,35 \%$ \\
CA PELE NÃO MELANOMA & 1 & $4,35 \%$ \\
CA PULMÃO & 1 & $4,35 \%$ \\
CA RETO & 1 & $4,35 \%$ \\
TU ABDOMINAL & 1 & $4,35 \%$ \\
Total & 23 & $100 \%$ \\
\hline
\end{tabular}

Fonte: Dados da Pesquisa.

\section{Discussão}

\subsection{Características demográficas e clinicas dos pacientes acometidos}

Participaram desta pesquisa 99 pacientes que apresentaram ao todo, 117 lesões de pele do tipo Lesão Tumoral, LPP e UTK. Dentre esta população estudada houve uma pequena predominância do sexo feminino com cerca de 52,53\%, na faixa etária entre 60 anos ou mais (53,64\%), onde as lesões mais encontradas foram do tipo Tumoral. Há uma maior prevalência de mulheres na faixa etária de maiores de 60 anos, de cânceres de mama e cabeça e pescoço, seguidos dos cânceres genitais e anal (INCA, 2019).

Com relação as LPP's, um estudo que Avaliou a incidência e fatores de riscos associados à queda e à lesão por pressão em unidade clínica de um hospital Universitário do rio de janeiro em 2018, também chegou ao resultado de maioria do sexo feminino $(51,6 \%)$ e de patologia relacionadas a doenças cardiocirculatórias e oncológicas, representando 43,9\% e 35,0\%, respectivamente (Cedraz et al., 2018).

Os cânceres de maior incidência no estado do Pará são mama e colo uterino (para mulheres) com uma média 780 casos por 100 mil habitantes e próstata para os homens, com uma média de 980 casos por 100 mil habitantes. Para o câncer de um modo geral a idade de maior prevalência é a partir dos 50 anos, assim como a idade aumenta também o risco de se desenvolver o câncer, somada a carga de exposições ao longo da vida e as próprias alterações biológicas resultantes do envelhecimento (INCA, 2019).

É importante ressaltar que anualmente há um aumento do número de casos de câncer no Brasil e no estado do Pará, o que deverá ser acompanhado de um aumento de pacientes em cuidados paliativos, logo acarretará num elevado número de pessoas com lesões tumorais e LPP, em fase final de vida, culminando no surgimento das UTK (WHO, 2018). Diante deste fato, se faz necessário que o corpo de enfermagem, onde estão os profissionais responsáveis pelos cuidados gerais e curativos diários destes pacientes, saibam reconhecer e manejar estes tipos de lesões.

Este estudo identificou que a maioria dos pacientes eram de baixa instrução, o que se faz refletir que o profissional enfermeiro responsável por estes pacientes e seus familiares, deve ter além dos conhecimentos sobre os manejos com estas lesões de pele, deve saber utilizar de forma impecável a ferramenta de comunicação, pois estas lesões podem se modificar, anunciando o fim de vida destes pacientes. Silva e Veloso (2019) abordam que a formação acadêmica dos enfermeiros ainda é focada e intensificada no cuidado para a promoção, recuperação e preservação da vida, o que os trona sem o devido preparo, técnico e psicologicamente para enfrentar os processos de morte e morrer.

Em estudo realizado por Bastos et al. (2018), nesta mesma instituição de saúde onda esta pesquisa foi realizada, se analisou 234 prontuários retrospectivamente no período de 2010 a 2014, observou-se que os níveis de escolaridade naquela época já eram baixos, visto que 38,91\% dos pacientes tinham apenas o ensino fundamental incompleto. 


\subsection{Características das lesões e produtos utilizados para controle de sintomas}

Neste estudo o sintoma mais frequente entre as lesões estudadas foi o exsudato e o odor ocorreu em $35 \%$, dentre todas as lesões estudadas, podendo estar relacionado ao estadiamento das mesmas pois encontravam-se em estágio inicial.

$\mathrm{O}$ tratamento de feridas em pacientes de cuidados paliativos, não visa a cicatrização da lesão, em virtude do baixo potencial de cura e da diminuição da expectativa de vida. O olhar sobre essas lesões volta-se ao controle de sintomas, buscando conforto e qualidade de vida. O agravamento do quadro clinico do paciente, favorece a deterioração progressiva da ferida, e em consequência disso, os sintomas podem ser de difícil controle, tais como, o odor, elevados níveis de exsudado, dor e hemorragia (Ferreira Junior; Polakiewicz; Fuly, 2019). Dentre essas lesões temos: ferida tumoral, lesões por pressão e úlcera terminal de Kennedy, as quais foram abordadas neste estudo.

O odor é um problema que gera graves impactos psicológicos, por despertar sensações de náuseas e consequentemente isolamento social. O impacto negativo do odor, ocasiona tristeza e angústia. A proliferação bacteriana é associada a este sintoma, logo a lesão com essa característica precisa de avaliação específica. O uso local de metronidazol tópico (pomada, creme, pó, solução) e sistêmico, bicarbonato de sódio e soluções antissépticas ajudam no controle de odor. Além de uso de curativos com carvão ativado, uma adequada oclusão da ferida e a adoção de medidas para amenizar o odor no ambiente, como o uso de aromas dentre outras. Entretanto, o uso de hidrocolóides e os alginatos podem levar a produção de odor (Santos et al., 2019).

A exsudação das lesões está relacionada diretamente com o odor. Ou seja, quando há uma redução de exsudato, é possível controlar e reduzir odor, proteger a pele perilesão, aumentando o conforto e auto-estima do paciente. Como opção, pode-se aplicar curativos absorventes, tais como as espumas de poliuretano, hidropolímeros, alginato de cálcio, a carboximetilcelulose sódica e o carvão ativado. O Óxido de Zinco é recomendado para proteger os bordos da ferida e a pele perilesional sendo um produto barreira, devido criar uma película polimérica na região aplicada, protegendo a pele de substâncias irritantes (Firmino, 2005).

Ao falarmos em hemorragias, deve-se levar em consideração primeiramente a prevenção de traumas nos tecidos presente no leito das feridas, no momento do curativo. A umidificação do leito da ferida obrigatoriamente deve ser realizada antes da remoção do curativo, assim como a utilização de curativos não aderentes (Lisboa; Valença, 2016).

As feridas sangrantes, tem o alginato de cálcio é o material de primeira escolha especialmente se estas se apresentarem exsudativas. Este ao absorver o exsudado forma um gel viscoso, em resultado de um processo físico de troca de íns cálcio presentes no curativo e íons de sódio presentes no exsudado da ferida. Nesse processo, o alginato de cálcio fornece cálcio ao leito da ferida, possuindo assim propriedades hemostáticas, para além de promover o alívio da dor, através da criação de um ambiente úmido, que por sua vez, umedece as terminações nervosas, evitando a propagação de estímulos dolorosos (Lisboa; Valença, 2016). A adrenalina é uma indicação para usar no leito da ferida, porém usada de forma cuidadosa, pois pode originar necrose isquêmica. Em hemorragias moderadas e intensas, pode-se fazer compressão local, hemostáticos ou ácido aminocapróico (Santos et al., 2019).

A presença de tecido desvitalizado na ferida requer do profissional a avaliação quanto ao desbridamento. Geralmente, o desbridamento agressivo não é recomendado em feridas que não cicatrizam. Após análise criteriosa, o desbridamento conservador pode ser adequado para reduzir necrose frouxa e o odor associado. A finalidade do desbridamento conservador não é a cicatrização, e sim a redução do risco de infecção (Agra et al., 2017).

A dor é um sintoma muito presente nas lesões de pacientes em cuidados paliativos, sendo necessário também um curativo adequado para reduzir o trauma e a dor na remoção. Neste estudo, a dor como sintoma não foi avaliada devido a população e estudada, alguns pacientes com alteração no nível de consciência poderiam não dar com precisão o nível de dor. Uso de gaze umedecida, analgésico e a utilização de morfina tópica e outros opióides ainda é controversa (Martins; Souza; 
Salgado, 2020).

A apresentação de um desses sintomas pode representar ao paciente, estar fora dos "padrões" impostos pela sociedade, tornando -se um ser diferente. Ter uma lesão crônica significa mudanças na vida tanto dos pacientes como de seus familiares. As dificuldades estão desde no acesso aos serviços de tratamento especializados, transporte, à educação, alimentação adequada e a manutenção adequada dos cuidados com ferida em casos de pacientes que estão em domicilio. Essas pessoas carregam o nervosismo, improdutividade, culpa, imperfeição, inutilidade, frustração e solidão, acarretando em isolamento social (Agra et al., 2017).

Os recursos utilizados com a saúde associado às úlceras crônicas, são altos, como: os materiais técnicos e à elevada dispensação de horas de enfermagem para os cuidados a este tipo de cliente. No Brasil, o custo com a saúde é elevado e vem crescendo em aceleradamente, resultando na dificuldade para manter a sustentabilidade do sistema de saúde, intensificada pela atual crise econômica mundial.

\subsection{Análise dos óbitos ocorridos em pacientes que apresentaram os três tipos de lesões}

Houveram 44 casos de óbito no conjunto de todos os pacientes portadores das três lesões estudadas (99 pacientes), dos quais nos casos das LPP, morreram $23(82,1 \%)$ pacientes, onde estes apresentaram tempo de vida após o término da coleta de dados de 12 dias e o que mais tempo viveu, alcançou 195 dias (6,5 meses). Estes pacientes ainda que portassem LPP de estadiamento 1 e 2 (LPP de pele íntegra à parcialmente exposição da derme), lamentavelmente possuíam PPS $\leq 30 \%$.

No caso dos portadores de Lesão Tumoral (67 pacientes), 17 (25,4\%) participantes evoluíram a óbito com mediana de tempo de vida após o término da coleta de dados de 61 dias, onde o estadiamento dessas lesões eram de 3 a 4 (lesões grandes, profundas e avançadas), e que também o PPS se manteve $\leq 30 \%$.

Castro et al. (2017), aborda sobre as diversas práticas assistenciais são executadas junto aos pacientes com câncer avançado no âmbito dos cuidados paliativos. Dentre elas, destaca-se o atendimento aos pacientes com feridas tumorais, que são responsáveis por acometer a pele e desfigurar o corpo, tornando-se friáveis, dolorosas, com sinais clínicos e sintomas limitantes, presentes, na maioria dos casos, nos últimos seis meses de vida.

Em se tratando dos óbitos nos casos em que os pacientes apresentaram UTK, a ocorrência foi de 100\%. Um resultado esperado, até pelo fato deste tipo de lesão ser conhecida como preditiva do processo de fim de vida. Estes pacientes apresentaram mediana do tempo de vida após o término da coleta de dados de 9 dias, com PPS $\leq 20 \%$.

Maia (2018), menciona a existência de 4 tipos de feridas em cuidados paliativos mais comuns. Assim seguem, as LPP bastante conhecidas; as feridas consideradas suspeitas de lesões profundas, que possuem coloração púrpura ou acastanhada, pele íntegra ou formação de vesículas de conteúdo sanguíneo, ocorrem em tecidos moles resultantes de pressão e/ou cisalhamento, podem ser dolorosas, a perda da espessura tecidual pode ser total, sendo a profundidade desta lesão apenas determinada quando se remove o tecido, pois este se encontra necrótico e cobrindo a lesão; As feridas malignas, oriundas de cânceres avançados que atravessam a superfície da pele; o último grupo é composto pelas úlceras diabéticas, úlceras venosas e arteriais e as feridas traumáticas, onde estão incluídas as UTK, que são um tipo de LPP inerentes à fase final.

Segundo Franck (2016), a falência crônica da pele é um evento onde pele e tecidos subjacentes morrem devido à falta de perfusão, que ocorre com o avançar de uma doença crônica. Isto se deve devido a perda da capacidade funcional do organismo como um todo, ou seja, quando o final da vida se aproxima, todos os sistemas do corpo entram em inatividade progressiva causando desnutrição tecidual generalizada, levando a perda de tecido subcutâneo e massa magra, assim como em falência da pele, pois neste momento ocorre o desligamento dos órgãos devido a circulação na tentativa de manter a vida utiliza a estratégia de priorizar os órgãos vitais.

O desenvolvimento de UTK é um indicador de que a morte ocorrerá de algumas horas a 6-8 semanas. E, além disso, o 
correto diagnóstico da UTK permite proteger os profissionais de saúde de negligência do aparecimento de UP na região sacrococcígea (Yastrub, 2010).

O que se sabe a respeito das UTK é que elas pertencem ao conjunto de Alterações da pele ocorridas na fase final de vida, conhecidas como SCALE (Skin Changes at the Life's End). Em abril 2008, em Chicago ocorreu um painel internacional com 18 especialistas para discutir este tema, de onde foi resolvido um consenso para avaliação e cuidado com esses tipos de lesões. O Consenso Scale aborda aspectos tais como: mudanças fisiológicas da pele no final da vida, cuidados centrados no paciente, comunicação com a equipe e cuidadores, entre outros (Franck, 2016).

Os princípios dos Cuidados Paliativos se aproximam dos posicionamentos preconizados pelo consenso Scale. Por fim o consenso além de estimular os esforços em manter cuidados que previnam lesões e até mesmo quando possível, melhorem as condições da pele, também visa considerar custos e benefícios, sejam estes econômicos ou físicos ou sociais que sejam uteis nesta etapa da vida.

\section{Conclusão}

Com relação ao perfil demográfico: as mulheres, de faixa etária $\geq 60$ anos, de baixa escolaridade, com diagnóstico de câncer de pele não melanoma seguido do câncer de mame e pênis. As lesões ocorreram em maior frequência na região sacra.

Em se tratando das Lesões Tumorais, o que surpreendeu foi o número de lesões em estadiamento inicial, o que as vezes passa despercebido pela equipe de enfermagem, pelo fato de que estas feridas chamam atenção, na maioria das vezes, quando são extensas e com odores intensos. Este fato pode retardar orientações que devem ser iniciadas o mais precocemente possível, quanto aos cuidados e manejos inerentes a este tipo de ferida, além das comunicações a respeito do nível e estadiamento do câncer, assim como a finalidade do tratamento.

No que se refere aos pacientes que desenvolveram LPP e UTK, houve um resultado de óbitos semelhantes, mesmo que as LPP ocorram em estadiamento inicial em sua grande maioria, porém estes participantes apresentavam um PPS baixo e também parecidos, $\leq 30 \%$, o que provavelmente contribuiu para a mediana de tempo de vida em torno de 12 e 9 dias, respectivamente. Estas especificidades dos cuidados paliativos oncológicos como, manejo de lesões de pele, comunicação empática, avaliação e identificação da fase final de vida, exige que o enfermeiro tenha qualificação e habilidades para lidar com este dia-a-dia junto a pacientes e seus familiares.

Esta pesquisa tem muito a contribuir para o local do estudo, para a comunidade científica em geral e para a enfermagem, pois além de ser a primeira que avaliou os pacientes em cuidados paliativos com os três principais tipos de lesões de pele no estado do Pará, com apoio dela poderá abrir possibilidades para planejamento de ações e políticas públicas.

\section{Referências}

Agra, G., de Souza Medeiros, M. V., de Brito, D. T. F., de Andrade, F. L. M., Pimentel, E. R. S., \& Costa, M. M. L. (2017). Conhecimento e prática de enfermeiros no controle de feridas neoplásicas. Revista Enfermagem Atual In Derme. https://revistaenfermagematual.c om.br/index.php/revista/article/view/549

Bastos, B. R., Pereira, A. K. D. S., Castro, C. C. D., \& Carvalho, M. M. C. D. (2018). Perfil sociodemográfico dos pacientes em cuidados paliativos em um hospital de referência em oncologia do estado do Pará, Brasil. Revista Pan-Amazônica de Saúde, 9(2), 31-36. http://dx.doi.org/10.5123/s217662232018000200004

Blanes, L., \& Ferreira, L. M. (2016). Prevenção e tratamento de úlcera por pressão. Editora Ateneu.

Carvalho, E. S. S., \& Amaral, J. B. (2013). Perda da integridade cutânea nos processos de finitude: medidas de prevenção, proteção e controle de danos. Enfermagem em cuidados paliativos: cuidando para uma boa morte. Martinari.165-94.

Castro, M. C. F., Santos, W. A., Fuly, P. D. S. C., Santos, M. L. S. C., \& Ribeiro-Garcia, T. (2017). Intervenciones de enfermería para pacientes oncológicos con olor fétido en herida tumoral. Aquichan, 17(3). https://revistas.unisabana.edu.co/index.php/aquichan/article/view/5208

Cedraz, R. O., Gallasch, C. H., Pérez Junior, E. F., Gomes, H. F., Rocha, R. G., \& Mininel, V. A. (2018). Gerenciamento de riscos em ambiente hospitalar: incidência e fatores de riscos associados à queda e lesão por pressão em unidade clínica. Escola Anna Nery, 22(1). https://doi.org/10.1590/2177-9465-EAN- 
Research, Society and Development, v. 10, n. 6, e7510615350, 2021

(CC BY 4.0) | ISSN 2525-3409 | DOI: http://dx.doi.org/10.33448/rsd-v10i6.15350

\section{7-0252}

Firmino, F. (2005). Pacientes portadores de feridas neoplásicas em serviços de cuidados paliativos: contribuições para a elaboração de protocolos de intervenções de enfermagem. Revista Brasileira de Cancerologia, 51(4), 347- 359. http://www1.inca.gov.br/rbc/n_51/v04/pdf/revisao6.pdf

Firmino, F. (2011). Quando a cicatrização não é a meta. In Silva, R. C. L. et al. Feridas: fundamentos e atualizações em enfermagem.. Yendis. 387 - 400.

Franck, E. M. (2016). Alterações de pele em pacientes em cuidados paliativos na terminalidade da doença e final da vida: coorte prospectiva. Dissertação de Mestrado, Escola de Enfermagem, Universidade de São Paulo, https://doi.org/10.11606/D.7.2017.tde-17052017-112324

Haisfield-Wolfe, M. E., \& Baxendale-Cox, L. M. (1999, July). Staging of malignant cutaneous wounds: a pilot study. In Oncology nursing forum. 26(6), 10551064). https://europepmc.org/article/med/10420423

Instituto Nacional de Câncer José Alencar Gomes da Silva. (2018). Estatística do Câncer. http://www.epi.uff.br/wp-content/uploads/2013/08/estimativaincidencia-de-cancer-no-brasil-2018.pdf

Junior Ferreira, J., Polakiewicz, R. R., \& Fuly, P. D. S. C. (2018). Feridas tumorais e suas implicações para o cuidado de enfermagem. Revista Enfermagem Atual In Derme, 85(23).

Lima, A. F. C., Castilho, V., Baptista, C. M. C., Rogenski, N. M. B., \& Rogenski, K. E. (2016). Custo direto dos curativos de úlceras por pressão em pacientes hospitalizados. Revista Brasileira de Enfermagem, 69(2), 290-297. https://doi.org/10.1590/0034-7167.2016690212i

Lisboa, I. N. D., \& Valença, M. P. (2016). Caracterização de pacientes com feridas neoplásicas. Estima-Brazilian Journal of Enterostomal Therapy, 14(1). https://www.revistaestima.com.br/index.php/estima/article/view/116

Maia, F. S. (2018). Feridas em Cuidados Paliativos: Resultados de um Estudo sobre Úlceras Terminais de Kennedy. Dissertação para obtenção do grau de Mestre em Cuidados Paliativos, Faculdade de Medicina da Universidade do Porto, Portugal.

Marconi, M. A., \& Lakatos, E. M. (2017). Metodologia do Trabalho Científico. (8a ed.), Atlas, p. 256.

Martins, T. C. F., de Souza, L. M., \& Salgado, P. O. (2020). Fatores relacionados ao odor de feridas tumorais: Uma revisão integrativa. Brazilian Journal of Health Review, 3(4), 9875-9889. https://doi.org/10.34119/bjhrv3n4-218

Polit, D. F., \& Beck, C. T. (2019). Fundamentos de pesquisa em enfermagem: avaliação das evidências para a prática clínica da enfermagem. (9a ed.), Artmed.

Ripley, K. R., \& Collier, M. (2017). Managing tissue viability issues in patients with cancer approaching the end of life. Nursing Standard, 31(25). https://doi.org/10.7748/ns.2017.e10621

Santos, W. A., Fuly, P. D. S. C., Souto, M. D., dos Santos, M. L. S. C., \& de Lima Beretta, L. (2019). Associação entre odor e isolamento social em pacientes com feridas tumorais malignas: estudo piloto. Enfermería Global, 18(1), 19-65. https://doi.org/10.6018/eglobal.18.1.322641

Silva, J. M., \& Veloso, V. L. (2019) Cuidados paliativos em paciente terminal de oncologia: desafios para o enfermeiro na unidade de terapia intensiva. Temas em Saúde. Fesvip. 177-191. https://temasemsaude.com/wp-content/uploads/2019/06/fesvip201911.pdf

World Health Organization. (2013). Cancer Palliative care. Fact sheet, n. 297. http://www.who.int/mediacentre/factsheets/fs297/en/index.html.

World Health Organization. (2014). Global atlas on Palliative care at end of life. http://www.thewhpca.org/resources/global-atlas-on-end-of-life-care.

Yastrub, D. J. (2010). Pressure or pathology: distinguishing pressure ulcers from the Kennedy terminal ulcer. Journal of Wound Ostomy \& Continence Nursing, 37(3), 249-250. https://doi.org/10.1097/WON.0b013e3181d737fa 